\title{
The meningeal branches of the superior cerebellar artery: a surgical observation study
}

\author{
Katsuya Umeoka, MD, PhD, ${ }^{1}$ Yutaka Takusakawa, MD, ${ }^{2}$ Shushi Kominami, MD, PhD, \\ Shiro Kobayashi, MD, PhD, ${ }^{1}$ and Akio Morita, MD, PhD ${ }^{3}$ \\ 1Department of Neurosurgery, Nippon Medical School, Chiba-Hokusou Hospital, Chiba; ${ }^{2}$ Department of Neurosurgery, \\ Tokyo Medical School, Tokyo; and ${ }^{3}$ Department of Neurosurgery, Nippon Medical School, Tokyo, Japan
}

\begin{abstract}
OBJECTIVE The tentorial branch of the posterior cerebral artery was first identified in a cadaver dissection study. However, the tentorial branch of the superior cerebellar artery (SCA) has not been clearly described in autopsy or normal anatomical studies. In this study, a dural branch of the SCA that was found during the surgical treatment of trigeminal neuralgia is described.
\end{abstract}

METHODS Between April 2011 and March 2014, 70 patients with idiopathic trigeminal neuralgia underwent microvascular decompression. The records of 58 patients were reviewed to investigate the meningeal branch of the SCA.

RESULTS The meningeal branch of the SCA was visualized in 15 of the 58 patients (25.9\%). In 4 patients, it was necessary to divide this branch in order to achieve decompression of the trigeminal nerve without eliciting postoperative neurological deficits.

CONCLUSIONS This is the first identification of the meningeal branch of the SCA in living subjects, and such branches were rather frequently found. Recognition of this branch is important for the management of lesions in the cerebellopontine angle and tentorial lesions, using either an open microsurgical or endovascular method.

http://thejns.org/doi/abs/10.3171/2014.12.JNS141190

KEY WORDS meningeal branch; superior cerebellar artery; surgical observation; anatomy

$I^{2}$ N 1965, Wollschlaeger and Wollschlaeger ${ }^{13}$ reported a meningeal branch of the posterior cerebral artery that supplied the medial aspect of the tentorium and the posterior portion of the falx cerebri, which is called the artery of Davidoff and Schechter. Based on their study of 10 barium-injected cadaver brains that were dissected with dural preservation, they documented the meningeal contribution of the superior cerebellar artery (SCA). However, Wollschlaeger and Wollschlaeger considered it to be a small arterial anastomosis from the SCA since they detected the tentorial branch of the SCA in only 1 cadaver.

Although the anatomy of the SCA has been reported, its tentorial branch has not been fully described. In a few case reports, this branch has been mentioned in the context of vascular tumors and vascular malformations involving the falcotentorial regions., 3,10,15 However, this branch has not been documented in normal anatomical studies. Here, we describe a dural branch of the SCA that was found during the process of transpositioning the SCA for the treatment of trigeminal neuralgia. To our knowledge, this is the first report of the surgical identification of the meningeal branch of the SCA.

\section{Methods}

Between April 2011 and March 2014, 70 patients with idiopathic trigeminal neuralgia underwent microvascular 
TABLE 1. Source of compression in 70 patients with trigeminal neuralgia

\begin{tabular}{lc}
\hline \multicolumn{1}{c}{ Source of Compression } & No. of Patients (\%) \\
\hline SCA & $33(47.1)$ \\
\hline AICA & $5(7.1)$ \\
\hline SCA \& AICA & $5(7.1)$ \\
\hline SCA \& vein & $10(14.3)$ \\
\hline Ipsilateral SCA & $2(2.9)$ \\
\hline SCA \& trigeminocerebellar artery & $2(2.9)$ \\
\hline Primitive cerebellar artery & $1(1.4)$ \\
\hline VA & $1(1.4)$ \\
\hline VA \& AICA & $2(2.9)$ \\
\hline VA, AICA, \& SCA & $1(1.4)$ \\
\hline Vein & $6(8.6)$ \\
\hline Tumor & $2(2.9)$ \\
\hline
\end{tabular}

$\mathrm{AICA}=$ anterior inferior cerebellar artery; $\mathrm{VA}=$ vertebral artery.

* Bifurcation on the proximal side of the trigeminal nerve.

decompression. All patients presented with a typical history of trigeminal neuralgia and were medically intractable. None had undergone previous radiosurgical and/or surgical treatment.

Preoperative MRI scans were examined to identify the relationship between the trigeminal nerve and the vessels. The sources of compression in 70 patients with trigemi- nal neuralgia are shown in Table 1 . In 58 of 70 patients (82.9\%) - 19 men and 39 women with ages ranging from 29 to 80 years (mean 61.2 years) - the SCA was compressed as it mobilized out to the tentorium. To obtain sufficient transposition of the SCA, it was dissected from the anterior pontine to the ambient segment, a procedure that prevented kinking of the SCA. We reviewed the intraoperative videos obtained in these 58 patients and investigated the meningeal branch of the SCA.

\section{Results}

In 15 of the 58 patients (25.9\%), the meningeal branch of the SCA was visualized (Fig. 1 and Video 1).

VIDEO 1. Description of the video images. This patient is a 36-yearold man with left trigeminal neuralgia. Preoperative MRI studies revealed the attachment of the SCA to the left trigeminal nerve. The operative procedure followed this timeline: 0:00-To facilitate adequate transposition, the ambient segment of the SCA was dissected as distally as possible. 0:05-The impression of the trigeminal nerve on the SCA was observed. 0:13-The attempt to transpose the SCA to the medial side of the tentorium failed due to tethering. 0:25-The meningeal branch of the SCA was noted. 0:33-The second attempt to transpose the SCA also failed due to tethering by a small branch. 0:49-The meningeal branch of the SCA was cut. 1:02-A Teflon-felt sling was placed around the SCA, and the vessel was transposed to the tentorium. 1:16-The SCA was fixed with fibrin glue. 1:19-The SCA was transposed successfully. Copyright Katsuya Umeoka. Published with permission. Click here to view with Media Player. Click here to view with Quicktime.

There was no predisposition with respect to sex or side
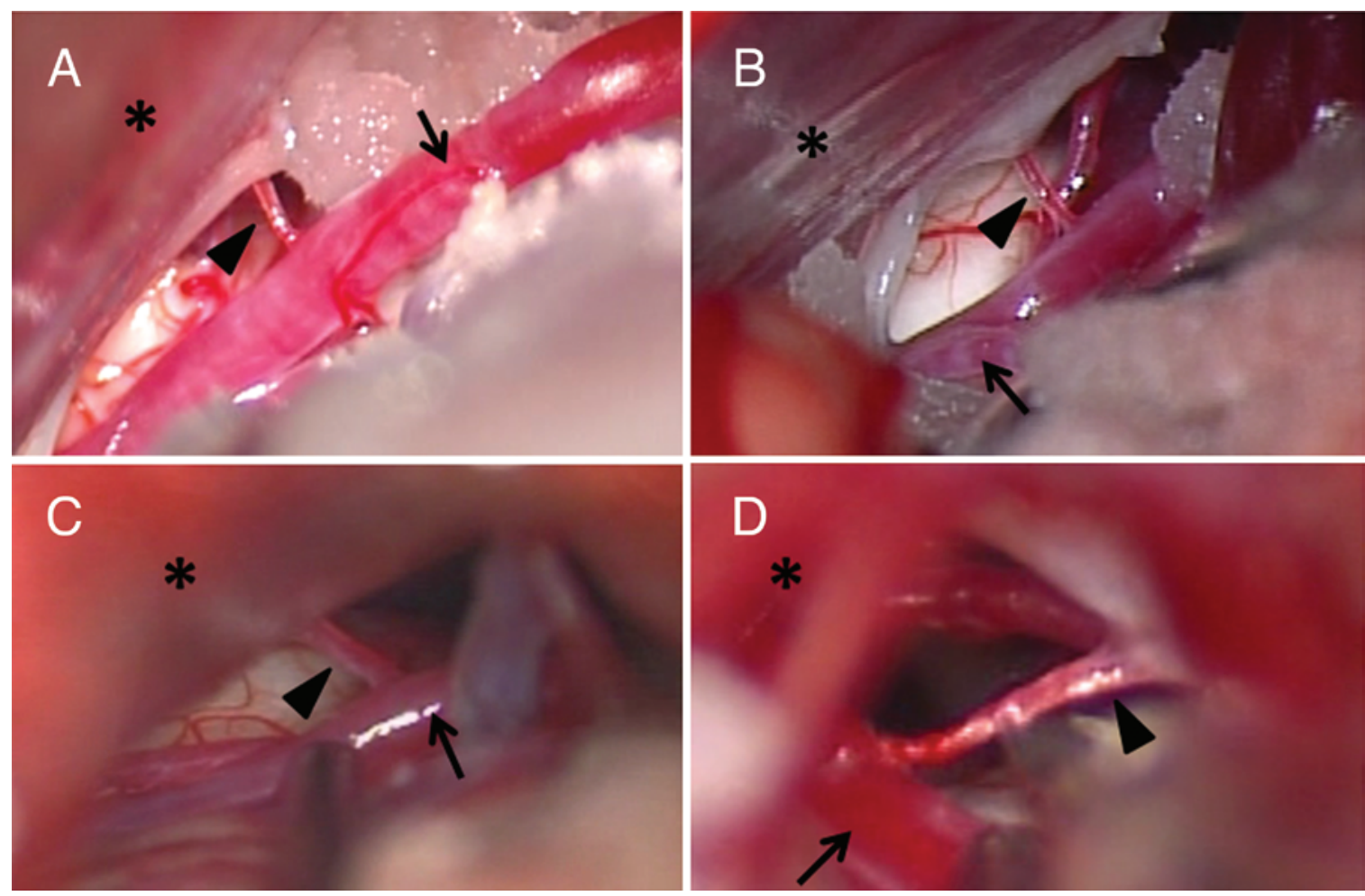

FIG. 1. Intraoperative photographs showing the tentorial branch (arrowheads) arising from the SCA (arrows) in the ambient cistern. The tentorial branch supplies the tentorium cerebri (asterisks). The side of trigeminal neuralgia is right (A), right (B), right (C), and left (D). 
TABLE 2. Clinical characteristics of the 58 patients in whom intraoperative video had been obtained

\begin{tabular}{ccc}
\hline \multirow{2}{*}{ Variable } & \multicolumn{2}{c}{ Meningeal Branch of the SCA } \\
\cline { 2 - 3 } & \multicolumn{1}{c}{ Presence } & Absence \\
\hline Total no. patients (\%) & $15(25.9)$ & $43(74.1)$ \\
\hline Mean age in yrs (range) & $62.5(29-78)$ & $59.3(32-80)$ \\
\hline Sex & & \\
\hline Male (\%) & $9(60)$ & $10(23.3)$ \\
\hline Female (\%) & $6(40)$ & $34(76.7)$ \\
\hline Affected side & & \\
\hline Right (\%) & $6(40)$ & $13(30.2)$ \\
\hline Left (\%) & $9(60)$ & \\
\hline Size & & \\
\hline$<1 \mathrm{~mm}$ & $12(80)$ & \\
\hline$>1 \mathrm{~mm}$ & $3(20)$ & \\
\hline
\end{tabular}

(Table 2). In 4 patients, we divided this branch for adequate transposition. None of these patients manifested neurological symptoms postoperatively.

\section{Discussion}

The tentorium cerebelli is supplied by the external carotid, internal carotid, and vertebral arteries. ${ }^{8}$ The petrosal insertion of the tentorium receives its vascular supply from the internal carotid artery and several branches of the external carotid artery. The blood supply at the occipital insertion of the tentorium is closely related to the supply of the falx cerebri. The tentorial branch of the posterior cerebral artery-the artery of Davidoff and Schechtercourses around the brainstem and below the free edge to enter the tentorium near the apex. ${ }^{13}$ It supplies the medial aspect of the tentorium and the posterior portion of the falx. The meningeal branch of the SCA, which was first described in $1965,{ }^{13}$ could not be identified in subsequent cadaveric studies., ${ }^{4,11,14}$ In such investigations, dye is commonly injected into the cerebral vasculature to improve the quality of the anatomical details. ${ }^{1,5,9}$ However, thrombotic occlusions and normal variability of the venous and arterial anatomy may yield an inaccurate representation of the anatomy of the normal arterioles. Because these vessels measure $1 \mathrm{~mm}$ or less, their inspection at cadaveric dissection may not be possible. Clinically, some authors have reported an enlarged tentorial branch of the SCA that supplied a posterior fossa dural arteriovenous fistula, vascular mass in the posterior part of the septum pellucidum, meningioma in the tentorial incisural region, or cerebellar hemangioblastoma. ${ }^{3,6,10,15}$ However, its origin and proximal segment have not been visualized in normal human vascular structure because this artery is so small that it is rarely seen on angiograms..$^{12,15}$

We encountered a tentorial branch arising from the lateral pontomesencephalic segment of the SCA during surgery for trigeminal neuralgia. We observed the SCA from the anterior pontine to the ambient division and transposed it toward the tentorium. During that procedure, a tentorial branch originating from the SCA was identified in 15 of 58 patients $(25.9 \%)$. Since the proximal branch of the tentorial artery of the SCA thwarted transposition of the SCA, we cut the tentorial branch to allow adequate transposition of the SCA. No patient manifested postoperative neurological symptoms. Based on our experience with these cases, we think this artery can be cut without eliciting neurological deficits. Since variations in the arterial anatomy in patients with idiopathic trigeminal neuralgia are considered normal, this is the first known report to describe the meningeal branch of the SCA as a frequent finding in the normal human vascular structure.

During surgery to the tentorium, recognizing the existence of a tentorial branch from the SCA is important. Before incising the tentorium, its free edge must be gently retracted and the meningeal branch of the SCA traveling through the ambient cistern must be identified. Then, the meningeal branch of the SCA can be safely occluded before incising the tentorium. Knowledge of the vascular anatomy is important for successful endovascular treatment. ${ }^{2}$ When performing cerebral angiography in patients with tentorial lesions, attention must be paid to both sides of the SCA.

\section{Conclusions}

This is the first known identification of the meningeal branch of the SCA in living subjects. Recognition of this branch is relevant for correct angiographic diagnosis and the endovascular management of tentorial lesions. Surgeons must be alert to the possible existence of the meningeal branch of the SCA in order to prevent profuse bleeding resulting from the tearing of this artery.

\section{References}

1. Alvernia JE, Pradilla G, Mertens P, Lanzino G, Tamargo RJ: Latex injection of cadaver heads: technical note. Neurosurgery 67 (2 Suppl Operative):362-367, 2010

2. Asari S, Maeshiro T, Tomita S, Kawauchi M, Yabuno N, Kinugasa K, et al: Meningiomas arising from the falcotentorial junction. Clinical features, neuroimaging studies, and surgical treatment. J Neurosurg 82:726-738, 1995

3. Awad IA, Little JR, Akarawi WP, Ahl J: Intracranial dural arteriovenous malformations: factors predisposing to an aggressive neurological course. J Neurosurg 72:839-850, 1990

4. Hardy DG, Peace DA, Rhoton AL Jr: Microsurgical anatomy of the superior cerebellar artery. Neurosurgery 6:10-28, 1980

5. Latarjet M, Douroux PE, Juttin P: [Use of plastic material in anatomical technic; anatomo-pathological aspects.] Lyon Chir 47:467-470, 1952 (Fr)

6. Lawton MT, Sanchez-Mejia RO, Pham D, Tan J, Halbach VV: Tentorial dural arteriovenous fistulae: operative strategies and microsurgical results for six types. Neurosurgery 62 (3 Suppl 1):110-125, 2008

7. Martins C, Yasuda A, Campero A, Ulm AJ, Tanriover N, Rhoton A Jr: Microsurgical anatomy of the dural arteries. Neurosurgery 56 (2 Suppl):211-251, 2005

8. Merland JJ, Bories J, Djindjian R: The blood supply of the falx cerebri, the falx cerebelli and the tentorium cerebelli. J Neuroradiol 4:175-202, 1977

9. Sanan A, Abdel Aziz KM, Janjua RM, van Loveren HR, Keller JT: Colored silicone injection for use in neurosurgical dissections: anatomic technical note. Neurosurgery 45:1267-1274, 1999 
10. Weil AG, McLaughlin N, Denis D, Bojanowski MW: Tentorial branch of the superior cerebellar artery. Surg Neurol Int 2:71, 2011

11. Weinstein M, Stein R, Pollock J, Stucker TB, Newton TH: Meningeal branch of the posterior cerebral artery. Neuroradiology 7:129-131, 1974

12. Weinstein MA, Duchesneau PM, Dohn DF: Angiographic identification of the meningeal branch of the posterior cerebral artery. AJR Am J Roentgenol 128:326-327, 1977

13. Wollschlaeger PB, Wollschlaeger G: [An infratentorial meningeal artery.] Radiologe 5:451-452, 1965 (Ger)

14. Zeal AA, Rhoton AL Jr: Microsurgical anatomy of the posterior cerebral artery. J Neurosurg 48:534-559, 1978

15. Zhou LF, Chen L, Song DL, Gu YX, Leng B: Tentorial dural arteriovenous fistulas. Surg Neurol 67:472-482, 2007

\section{Author Contributions}

Conception and design: Umeoka. Acquisition of data: Umeoka. Analysis and interpretation of data: Umeoka. Drafting the article:
Umeoka, Takusakawa, Kominami, Kobayashi. Critically revising the article: Umeoka. Reviewed submitted version of manuscript: all authors. Approved the final version of the manuscript on behalf of all authors: Umeoka. Administrative/technical/material support: Umeoka. Study supervision: Umeoka, Morita.

\section{Supplemental Information Videos}

Video 1, Media Player. http://mfile.akamai.com/21490/wmv/ digitalwbc.download.akamai.com/21492/wm.digitalsource-naregional/jns14-1190_video_1.asx.

Video 1, Quicktime. http://mfile.akamai.com/21488/mov/ digitalwbc.download.akamai.com/21492/qt.digitalsource-global/ jns14-1190_video_1.mov.

\section{Correspondence}

Katsuya Umeoka, Department of Neurosurgery, Nippon Medical School, Chiba-Hokusou Hospital, 1715 Kamagari, Inzai City, Chiba 270-1694, Japan. email: katsuya@nms.ac.jp. 